\title{
Fiber resin matrix composites: nature's gift
}

\author{
M. S. Liew ${ }^{1}$, A. H. Shamsuddin ${ }^{2}$ \& G. Z. Yew ${ }^{1}$ \\ ${ }^{1}$ Civil Engineering Department, \\ Universiti Teknologi PETRONAS, Malaysia \\ ${ }^{2}$ Centre for Renewable Energy, College of Engineering, \\ Universiti Tenaga Nasional, Malaysia
}

\begin{abstract}
Timber is a natural product and is a material of choice in the construction industry because of its versatility as a temporary support material and as a finished material. It can be designed as load bearing as well as non-load bearing material. Alternatively, with the advent of compressed wood developed from the waste of the timber industries, a parallel approach is made to study the application of wood plastic composites (WPC) which have been developed for the past five years. The quality of the WPC varies due to the varying type of the sawdust derived from mixtures of hard and soft wood. The main compound in simulating natural wood is fiber which can be found naturally from the empty fruit bunches (EFB) derived from the oil palm industries found in Malaysia and Indonesia, two of the largest crude palm oil producers in the world. Malaysia and Indonesia contributed in excess of 100 million tons of waste generated from the Oil Palm Industry in the form of empty fruit bunch (EFB) and other fibrous waste generated in the extraction of crude palm oil. The micron sized fibers are integrated with selected grade resins including recycled resins if necessary and other non-carcinogenic chemicals stabilizers to form fiber resin matrix composites (FRMC). These FRMC can be used as construction materials and interior architectural finishes. FRMC materials are eco-friendly, sparing many trees and promote green technology. FRMC have been tested and exhibited superior mechanical properties to that of hard wood. Cost comparison had indicated that FRMC remains competitive to the hard wood.

Keywords: fiber resin, composites, hard wood, empty fruity brunches, green technology, mechanical properties.
\end{abstract}




\section{Introduction}

Timbers are widely used worldwide in the construction industry, product application industry, and even in the logistic industry such as the wooden crates and the wooden pallets. The rapid depletion of rain forest leading to global warming [1] calls for an alternate and sustainable replacement for timber. Many developed nations are now developing the wood composites as replacement for timber. This replacement product is known generically as wood plastic composites (WPC). In the global CEO survey [2], it was found that $80 \%$ of the leading CEOs are in favor of sourcing for alternative sustainable and renewable products in combating global warming if such products exist.

As an alternate material, WPC is currently being produced through the extrusion or the injection molding process in making different finished profiles for use as interior finishes giving rise to aesthetically pleasing architectural looks. The market entry of WPC is accepted with only lukewarm reception due to several factors. These factors include changing conventional mindset of end users with craving for timber, unscrupulous claim by some producers of WPC leading to questionable product performance, lack of product education and awareness. In addition, WPC is still in its infancy stage requiring continual technical development in a bottom line business environment.

\section{Micron sized sustainable and renewable fiber resources from the palm oil industry}

Statistically, Malaysia has in excess of 4.2 million hectares of oil palm plantation supported by over 460 oil palm mills of varying processing capacity typically in the range of 10 to 120 tonnes of fresh fruit bunches (FFB) per hour. The majority of the oil palm mills is privately owned and typically purchased these FFB from the small land holders since they do not have any oil palm plantation to support their processing needs. On an annual basis, more than 80 million tons of FFB are processed by the oil palm mills. The production of FFB by the oil palm trees fluctuates throughout the year and is affected by the seasonal trend found locally. In the production of palm oil through a pressing process, the waste product in the form of EFB is generated in huge must be taken care of by the oil palm mills.

Table 1: $\quad$ Solid wastes production rate from a mill processing 60 metric tons per hour of FFB.

\begin{tabular}{|c|c|c|}
\hline \multirow{2}{*}{ Waste Type } & \multicolumn{2}{|c|}{ Amount Produced, kg/hr } \\
\cline { 2 - 3 } & Wet & Dry \\
\hline Palm Kernel Shell & 3340 & 3140 \\
\hline Mesocarp Fiber & 9160 & 6530 \\
\hline Empty Fruit Bunches & 14960 & 4910 \\
\hline
\end{tabular}


A 60 tons oil palm mill has a capacity to process 60 tons of FFB per hour and producing about $50 \%$ of waste from the processed FFB. These wastes are typically in the forms of EFB, mesocarp fibers and palm kernel shell. The compositions of these wastes are given in Table 1 [3]. All of the waste materials have high water content as seen from the wet and dry weight of the solid wastes shown in Table 1.

Of these wastes, the EFB is by far the most abundant compared with other wastes. Through several processes of cutting and pulverizing, the dried EFB with a minimum of 8 to $12 \%$ of moisture content can be converted into short to micron sized fibers $(<4 \mathrm{~mm})$. Other wastes such as the mesocarp fiber and palm kernel shell are used as biomass fuel by the oil palm mills for their heating needs in the production of steam and in domestic power generation as well which can be self sustaining in some cases.

Since most oil palm mills are privately owned, the waste EFB is transported off the mills by a third party for use in other applications. Typically, the unprocessed EFB is of low quality. The EFB is laden with $60 \%$ of moisture content and the EFB is normally use as landfill materials, incinerated to obtain the ash which may be blended as chemical or as organic fertilizer. Sometimes plantation owners left the EFB to rot in the plantation as a source of fertilizer to the land. All of the activities related to the EFB described above emit green house gases (GHG) leading to global warming.

To overcome the above mentioned GHG emission from EFB, an approach to convert the EFB to short fibers and micron sized fibers provides a definite solution on the use of EFB. The objective of this paper is to discuss the development of FRMC from EFB and is now discussed herein.

\section{Development of FRMC}

The micron sized fibers or commonly known as pulverized fibers are produced from short fibers which have been pulverized in several stages using rotary sieves to produce certain sizes of fibers which are dependent on the types of application of the FRMC. The pulverizing process is of low volume typically due to the very low mass of the fibers being pulverized. Nevertheless, all fibers are derived from EFB initially. Logistically, it is difficult to transport EFB since it is bulky and carries excessive moisture $(>60 \%)$. The initial quality of EFB is of utmost importance since only high quality fibers can be converted into pulverized fibers. It was found that any EFB which have been left unattended to in excess of 36 hours can no longer be processed into high quality fibers due to decomposition of the EFB by microbes. The typical transfer cost of EFB ranges from USD 2.50 to USD 5.00 per ton.

This EFB needs to be processed further through shredding, hammer milling, drying, pulverized, and rotary sieving. This paper presents current effort to develop processing technology to transform low quality EFB into high quality pulverized fibers or micron sized fibers. These fibers are then compounded further with resins derived from the petrochemical industries and other chemical stabilizers to produce FRMC. The conversion of the micron sized fibers into 
FRMC resulted into a high end product which carries superior mechanical properties to the naturally found hard wood derived from the forest. Since these processes of pulverization are guarded trade secret, the authors will attempt to describe these processes in broad terms. These processes are now described.

The main processes involved in the production of pulverized fibers from EFB are the removal of moisture content through primary and secondary pressing process. This process involves fragmenting EFB into lumped mass and then the lumped mass of EFB is shredded into short fibers. These short fibers then go through wet sieving to remove any alien materials. The sieved wet short fibers are then desiccated and pulverized into short fibers of micron sizes of various gradation grades depending on its application as FRMC. The acceptable micron sized fibers are now ready for compounding with resins and other chemical stabilizers to produce FRMC through extrusion, injection, and heat molded processes. Typically, the continuous extrusion process is generally good for smaller product profiles of less than $300 \mathrm{~mm}$ in dimension. Larger product profiles can be obtained through homogeneous injection molding. Thinner section can be produced through heat molded process. Regardless, typically the thickness of a section must not be less that the longest pulverized fibers.

The dewatering process is invoked to ensure minimum amount of moisture is needed to be removed in the drying process to optimize the use of heat, a main production cost in the production of FRMC. The pressing method through the use of screw press is usually conducted by majority of the privately owned palm oil mills in the secondary oil recovery.

The pressing process typically removes between $50 \%-60 \%$ of the moisture content from the EFB. Typical example of EFB is shown in Figure 1. A press shredder is used to coarsely fragment the EFB into manageable short fiber with length of fibers less than $50 \mathrm{~mm}$. This process is the key departure from the production of long quality fibers which are typically longer than $100 \mathrm{~mm}$ in length to be of any commercial value.

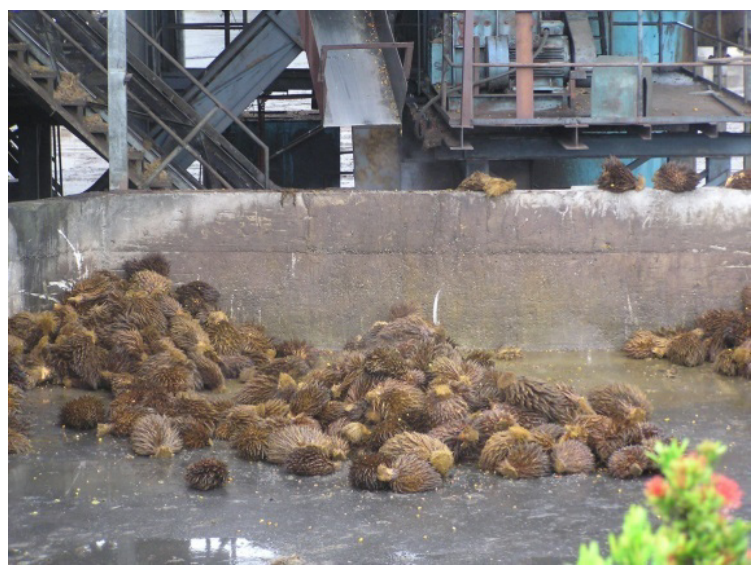

Figure 1: $\quad$ Empty fruit bunches, EFB. 
Shredding rate of up to 6 tons of EFB per hour is currently feasible. Typical example of shredder is shown in Figure 2.

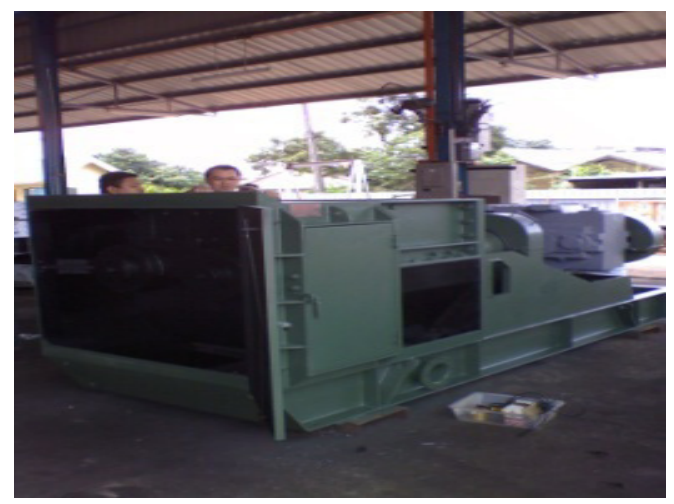

Figure 2: $\quad$ Shredder.

A segregator machine is used to loosen or break off lumpy short fiber. A rotary screener is used to separate wet short fiber from wet over sized fibers or wet long fibers. Oversized and long wet fibers are then recycled into the shredder machine to get the desired size. An example of a segregator machine is shown in Figure 3. Since the production of FRMC is currently being applied as intellectual properties (IP) through the authors' previous engagement, many support processes are not discussed herein. Only processes related to "milestone" achievement is discussed herein. Further, there are other processes which will only be mentioned briefly to ensure continuity in the paper presented herein.

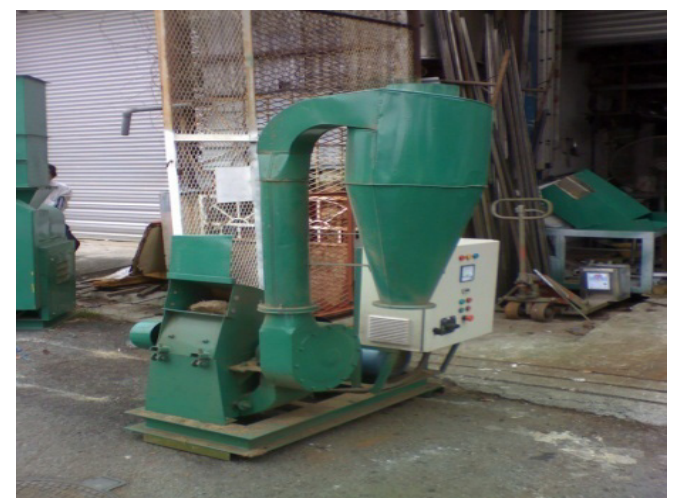

Figure 3: $\quad$ Segregator.

The short fibers are then dried through a non-linear drying process. The drying process is non-linear due to its fiber properties currently under investigation. 
A combination of heat management which includes drying rate and material bulk processing density must be observed to produce dry short fibers of high quality. The dried short fibers carry a moisture content of $8 \%$ typically. The dried short fibers are then pulverized into micron sized fibers through several available commercial machines. These machines are selected based on their ability to recognize the super light weight of the short fibers. A typical pulverizing rate is in the range of 50 to $250 \mathrm{~kg}$ per hour. This depends on the arrangement of the machines and the sieving processes which in itself must be optimized.

A mixing and compounding pre-heated silo is used to mix and compound the micron sized fibers with the resin and other chemical stabilizers in varying proportion dependent on the type of FRMC to be produced. Further reduction of moisture from the fibers will take place through the pre-heated compounding process. For example, in the production of structural profiles shown in Figure 4 made through extrusion process and technology, the structural strength of the $\mathrm{FRMC}$ is the key criteria in the mixing processes and proportion. A maximum of $70 \%$ of micron sized fibers shall be compounded with $30 \%$ of resins. On the contrary, a minimum of $40 \%$ of micron sized fibers can be compounded with $60 \%$ of resins to produce durable and sustainable profiles with superior quality and mechanical properties exceeding that of naturally found hard wood.

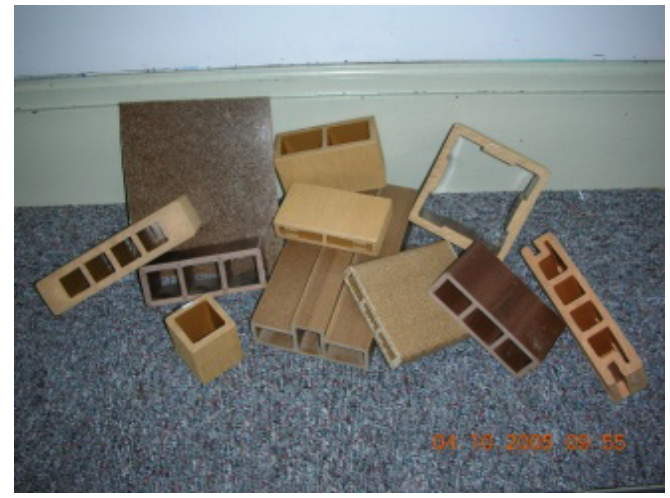

Figure 4: $\quad$ Typical structural profiles made from FRMC.

In extruding for the type of profiles desired, one must account for the type of finishes of the profiles, desired structural strength, thickness of the thin walled stiffeners of the profiles, and the application of the profiles. As such, the compounding process of the resins and the fibers must be performed correctly. This technological advancement is not discussed herein due to the applied intellectual properties. It is sufficient to state herein, that various resins, injection technology, and even heat forming technology were tested and found to be compatible with the materials forming the FRMC.

Figure 5 shows an example of an actual application of the profiles made from FRMC as an initial prototype. Other tested prototypes of the profiles are in 
making pallets, container decking, windows and door frame profiles. The challenges remain in the production capacity of the profiles and high capital cost. A typical mechanical properties of the profiles tested are summarized in Table 2.

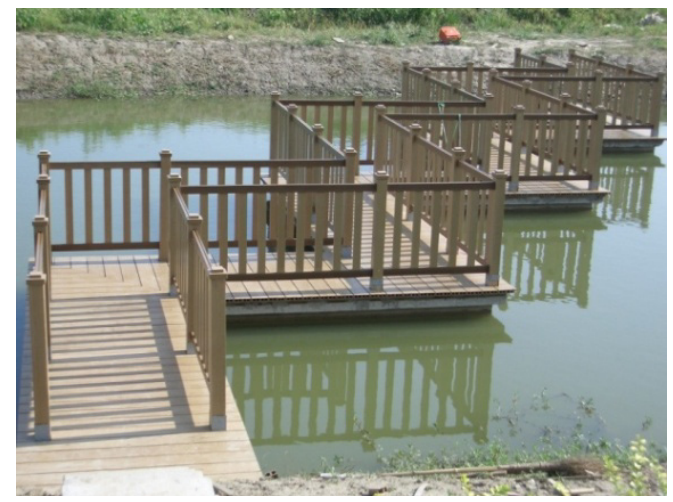

Figure 5: Actual application of profile.

Table 2: $\quad$ Typical mechanical properties of FRMC (50\% compound) and economic study.

\begin{tabular}{|c|c|c|}
\hline Structural Properties & \multicolumn{2}{|c|}{$\begin{array}{c}\text { Comparison of FRMC and } \\
\text { Hard Wood }\end{array}$} \\
\cline { 2 - 3 } & FRMC & Hard Wood \\
\hline Tensile Strength, MPa & 21 & 10 \\
\hline $\begin{array}{c}\text { Compression Strength, } \\
\text { Mpa (Parallel to Grain } \\
\text { for Hard Wood) }\end{array}$ & 36 & 18 \\
\hline Bending Stress, Mpa & 37 & 18 \\
\hline Water Absorption, \% & Max 1 & Min 6 \\
\hline Economic Study (RM) & & 4800 to 5500 \\
\hline Market Price (per ton) & 3800 to 4500 & NA \\
\hline Cost (per ton) & 2200 to 2700 & \multicolumn{2}{|c}{} \\
\hline
\end{tabular}

Durability of the FRMC remains competitive with hard wood under untreated condition. It is noted herein that the main competitive advantage of using FRMC is due to the sustainable and renewable nature of such application. Further, FRMC is homogeneous in its material mechanical properties and the quality can be controlled to produce high quality FRMC profiles. It can be formed into any shapes through the application of the mold which must be specially made to produce linear cooling properties rather than uniform cooling properties.

The challenges in the production of the FRMC profile is in the production rate itself. It was found that the production rate controls the pricing structure. Further research must be made to optimize and to enhance production rate which is beyond the scope of this paper presented herein. Further, the costs of resins are 
very much influenced by the market rates which are dependent on the petrochemical industries. Nevertheless, in the early stage of the research, recycled resins have been used and found to be compatible with the micron sized fibers except the final products are generally dark in color which may be visually prohibitive if aesthetics are the key feature of the final products. This is the main drawback although there are no significant differences on the mechanical properties in using recycled resins.

In the initial stage of the research, electron microscope was used to study up to 10000 times of the material structures. It was found that the size of the cavities or voids may be able to predict the strength of the FRMC profiles. Such study has great potential in the development of FRMC into other materials such as high strength low weight materials. This study is excluded from the paper presented herein.

\section{Summary}

Commercially, FRMC has a wide application similar to those of hard wood. FRMC is not competitive with the soft wood market especially in the production of logistic pallets where load capacity is not a consideration. Nevertheless, while wooden pallets are needed to fumigate before shipping internationally, FRMC is exempted from this procedure resulting in some savings on the shipping cost. While the simulated cash flow position is favorable even for the first year of production, the return period is in the range of 5 years due to the heavy capital investment on the high end machines.

The market availability and product entry have initial resistance due to the newness of such products. Nevertheless, the current market acceptability is vast since acceptance has been received on high structural strength profiles with durable capability.

\section{Acknowledgements}

The authors would like to acknowledge the Government of Malaysia for their support during the early stage of development on EFB when this research into FRMC was only an idea. The authors would like to express their gratitude to all the machine makers who have spent relentless hours in perfecting the design of locally made machines to cater for the processes described herein.

\section{References}

[1] http://www.undp.org.my/uploads/Renewable_Energy_Palm_Oil_Was te.pdf (Accessed on 3 February 2010).

[2] Price Water Coopers, $12^{\text {th }}$ Annual Global CEO Survey (2009).

[3] Shamsuddin, A.H., Palm oil by-products as alternative energy source. Proc. ASEAN Conf. on Energy Conservation, ASEAN Working Group on Nonconventional Energy Research, pp. 257-264, 1985. 
[4] Shamsuddin, A.H. \& Liew, M.S., High Quality Biofuel Briquette Production From Palm Oil Milling Solid Wastes. ASME $3^{\text {rd }}$ International Conference on Energy Sustainability ES 2009, San Francisco, California, 2009.

[5] MPOB, Malaysian Palm Oil Board, Empowering Change: Review of the Malaysian Oil Palm Industry 2006, Ministry of Plantation Industries and Commodities, Selangor, Malaysia, 2007.

[6] Shamsuddin, A.H. \& Sopian, K., Combustion of oil palm solid wastes in a fluidized bed combustor. Proc. of the $30^{\text {th }}$ Intersociety Energy Conversion Engineering Conference, ASME, Vol. 2, Paper No. RE-160, pp. 565-571, 1995.

[7] Hussin, A. et al., Thermochemical behavior of empty fruit brunches and oil palm shell waste in a circulating fluidized-bed combustor. Journal of Oil Palm Research, Vol. 18, pp. 210-218, June 2006.

[8] Nasrin, A.B. et al., Production of palm-based biomass briquettes. Malaysian Palm Oil Board Information Series, ISSN 1511-7871, June 2006. 